\title{
Mortality and complications of hip fracture in young adults: a nationwide population-based cohort study
}

Jeff Chien-Fu Lin ${ }^{1,2^{*}+}$, Cheng-Chun Wu ${ }^{2 \dagger}$, Chi Lo ${ }^{3^{*}}$, Wen-Miin Liang ${ }^{4,5}$, Chi-Fung Cheng ${ }^{5}$, Chang-Bi Wang ${ }^{5}$, Yu-Jun Chang ${ }^{5,6}$, Hsi-Chin Wu ${ }^{7,8}$ and Tsai-Hsueh Leu ${ }^{2}$

\begin{abstract}
Background: This study assessed the mortality and complications of hip fractures using in-patients aged 20-40 years from a nationwide population database in Taiwan.

Methods: Subjects were selected from Taiwan's National Health Insurance Research Database for the period 2000-2008, and these subjects were followed up until the end of 2010. A total of 5,079 (3,879 male and 1,200 female) subjects were admitted for the first time with primary diagnosis of hip fracture and treated with operation. We calculated the long-term overall survival rate and complication-free rate. We also assessed the risk factors for mortality and complications.

Results: The 1-month, 3-month, 6-month, 1-year, 2-year, 5-year, and 10-year complication-free rates were 98.3\%, 96.2\%, $94.5 \%, 86.8 \%, 80.4 \%, 75.3 \%$, and $73.5 \%$ for the entire cohort, respectively. The 10-year survival rates were 93.3\%, 91.8\%, and $94.5 \%$ for total cases, trochanteric fracture, and cervical fracture, respectively. The 10-year complication-free rates were $73.5 \%, 80.5 \%$, and $67.3 \%$ for total cases, trochanteric fracture, and cervical fracture, respectively. The risk factors for overall death were male, older age, and greater number of Charlson comorbidity index (CCI) comorbidities. The risk factors for complication were cervical fracture, and greater number of $\mathrm{CCl}$ comorbidities. Complications resulted in $42.83 \%$ of patients receiving internal fixation implants or prothesis removal and $2.01 \%$ underwent conversion to revision arthroplasty during follow-up.
\end{abstract}

Conclusions: The overall 10-year survival rate in hip fracture patients aged 20-40 years in Taiwan was over 90\%. The 10-year complication-free rates were around $70 \%$. Preventing the occurrence of severe complications after hip fracture among young adults is an important public health issue that warrants greater attention.

Keywords: Hip fracture, Complication, Mortality

\section{Background}

Most hip fractures occur in the elderly population and are associated with osteoporosis and simple falls [1]. Studies have reported that the 1-year mortality of hip fracture is around $20 \%-30 \%$ in the elderly population [1-9]. In contrast, hip fracture among young adults is uncommon and is generally caused by high-energy trauma [10-19]. Less than $10 \%$ of hip fractures occur among

\footnotetext{
*Correspondence: cflin.ntpu@gmail.com; lochichilo@gmail.com ${ }^{\dagger}$ Equal contributors

'Department of Statistics, National Taipei University, Taipei 10478, Taiwan ${ }^{3}$ Department of Hospitality Management, Chung Hua University, Hsinchu 30012, Taiwan

Full list of author information is available at the end of the article
}

young adults aged $<50-60$ years in North America [1,9]. The survival rate of hip fracture among young adults is $>90 \%[11-16,18,19]$. Only a few studies have recently explored the outcomes of hip fractures among young adults aged $<40$ years [10-19]. However, no population study has explored the long-term outcomes of hip fractures in young Asian adults. Accordingly, this study aimed to assess the short- and long-term rates of complications and mortality in hip fracture patients aged 20-40 years using a nationwide population database in Taiwan.

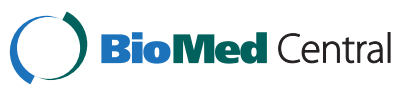

(C) 2014 Lin et al.; licensee BioMed Central Ltd. This is an Open Access article distributed under the terms of the Creative Commons Attribution License (http://creativecommons.org/licenses/by/2.0), which permits unrestricted use, distribution, and reproduction in any medium, provided the original work is properly credited. The Creative Commons Public Domain Dedication waiver (http://creativecommons.org/publicdomain/zero/1.0/) applies to the data made available in this article, unless otherwise stated. 


\section{Methods}

\section{Data source and subjects}

Taiwan's National Health Insurance (NHI) program was launched in 1995 and covers most of the population. The National Health Insurance Research Database (NHIRD) was established in 1997 and collects all claims of those insured in the NHI program. The NHIRD covered more then $99 \%$ of the entire population (>23 million) in 2013. Taiwan's Ministry of Health and Welfare (formerly the Department of Health) and the NHI Bureau maintain and verify the accuracy and completeness of the NHIRD. The data source in the present study was the NHIRD which was made available through the National Health Informatics Project, NHIP in Taiwan which provides scientists with datasets for research purposes. Data for all subjects aged $\geq 20$ and $<40$ years, who were admitted to hospitals between 1 January, 2000 and 31 December, 2008, were collected from the NHIRD. All subjects were followed up to death, exit from the NHI program, or the end of 2010. There were two inclusion criteria in this study: (i) the first discharge diagnosis code was hip fracture based on International Classification of Disease, Ninth Revision, Clinical Modification (ICD-9-CM) codes 820, $820.0,820.00,820.01,820.02,820.09,820.8,820.03$, $820.2,820.20$, or 820.21 ; and (ii) the operation code was surgery of internal fixation or hemiarthroplasty based on ICD-9-CM codes $79.15,79.35$, or 81.52 . The index date was the first admission date of hip fracture. The exclusion criteria were as follows: (i) in-patients admitted with pathological fractures with ICD-9-CM codes 733.14 or 733.15; or (ii) open hip fractures with ICD-9-CM codes $820.1,820.10,820.11,820.12,820.19,820.9,820.13$, $820.22,820.3,820.30,820.31$, and 820.32. Patients who had received an operation to treat the pelvis, femur, or hip regions before the index date were excluded to avoid confounding effects. More than $99 \%$ of the hip fractures in these young adults were caused by high-energy trauma.

\section{Ethical considerations}

All patients's data were all encrypted using the same encryption algorithm to cross-link the data while protecting the privacy of the patients. This study protocol was approved by the institutional review board (IRB) of China Medical University Hospital (protocol \# CMUH102REC2-012).

\section{Outcome measures}

The main outcome of this study was the complicationfree duration after operation for hip fracture. We also explored overall survival after hip fracture. The overall survival time was defined as the duration from the index date to the death date. Subjects alive at the end of study or lost to follow-up were treated as censored. Complication-free time was a composite outcome and was defined as the duration from the index date to the date that the first post-operative complication occurred. The post-operative complications included the occurrence of one or more complications, including (i) death within 90 days after index date, (ii) acute medical complications requiring admission to hospital for treatments within 90 days after the index date, and (iii) surgical complications requiring admission to hospital for additional surgical treatments after the index date. The acute medical complications included stroke, acute myocardial infraction, acute renal failure, pneumonia, pulmonary embolism, and sepsis that occurred within 90 days after the index date. Surgical complications included surgical site infection, conversion to arthroplasty or revision arthroplasty, internal fixation implant or prostheses removal, mechanical complications (including loss reduction, screw loosening or cutting out, skin irritation, implant broken/failure), dislocation, avascular necrosis of femoral head, malunion/ nonunion, and second hip fracture at the same site during the follow-up period. Subjects who were dead 90 days after the index date, or alive without any complication at the end of study were treated as censored. The comorbidities of subjects were retrieved before or at the time of the index date based on the Charlson comorbidity index (CCI) [20].

\section{Statistical analysis}

We estimated the survival rates based on the Kaplan-Meier method and complication-free rates (1 minus cumulative incidence function of complication) based on competing risk analysis. We explored the effects of risk factors on survival based on Cox's proportional hazards model. We explored the risk factors for complications based on the Fine and Gray model with sub-distribution hazard. Factors in the multivariable analysis included age, gender, type of hip fracture, type of operation and number of CCI comorbidities. Data management and calculation of hazard ratios (HRs) and sub-distribution hazard ratios (sHRs) were performed using the SAS System (version 9.2; SAS Institute, Cary, NC, USA).

\section{Results}

Between 2000 and 2008, 5,079 subjects were admitted for the first time with primary diagnosis of hip fracture and treated with operation. Among these patients, 2,905 (57.2\%) had cervical fracture, 2,174 (42.8\%) had trochanteric fracture, 3,879 (76.4\%) were male, 1,200 (23.6\%) were female, 4,901 (96.5\%) received internal fixation, and $178(3.5 \%)$ received hemiarthroplasty (Table 1). The 5 - and 10 -year survival rates were $95.3 \%$ and $93.3 \%$, respectively, for the entire cohort (Table 2). Moreover, the 5- and 10-year survival rates were $94.2 \%$ and $91.8 \%$ for trochanteric fracture and $96.1 \%$ and $94.5 \%$, respectively, for cervical fracture (Table 2). The major causes of death 
Table 1 Baseline characteristics of hip fractures among young adults in Taiwan

\begin{tabular}{|c|c|c|c|c|c|c|}
\hline & \multicolumn{2}{|c|}{ Total } & \multicolumn{2}{|c|}{ Trochanteric } & \multicolumn{2}{|c|}{ Cervical } \\
\hline & \multicolumn{2}{|c|}{$(\mathrm{N}=5,079)$} & \multicolumn{2}{|c|}{$(\mathrm{N}=2,174)$} & \multicolumn{2}{|c|}{$(\mathrm{N}=2,905)$} \\
\hline & $\mathrm{N}$ & $\%$ & $N$ & $\%$ & $\mathrm{~N}$ & $\%$ \\
\hline Age (Mean \pm SD) & \multicolumn{2}{|c|}{$31.07 \pm 5.94$} & \multicolumn{2}{|c|}{$31.52 \pm 5.80$} & \multicolumn{2}{|c|}{$30.73 \pm 6.01$} \\
\hline \multicolumn{7}{|l|}{ Gender } \\
\hline Male & 3879 & $(76.37)$ & 1788 & $(82.24)$ & 2091 & (71.98) \\
\hline Female & 1200 & $(23.63)$ & 386 & $(17.76)$ & 814 & $(28.02)$ \\
\hline \multicolumn{7}{|l|}{ Operation } \\
\hline Hemiarthroplasty & 178 & $(3.5)$ & 14 & $(0.64)$ & 164 & $(5.65)$ \\
\hline Internal fixation & 4901 & $(96.5)$ & 2160 & (99.36) & 2741 & $(94.35)$ \\
\hline \multicolumn{7}{|l|}{ CCl No. } \\
\hline 0 & 4642 & (91.4) & 1940 & (89.24) & 2702 & (93.01) \\
\hline 1 & 282 & $(5.55)$ & 146 & $(6.72)$ & 136 & $(4.68)$ \\
\hline$\geq 2$ & 155 & $(3.05)$ & 88 & $(4.05)$ & 67 & $(2.31)$ \\
\hline \multicolumn{7}{|l|}{ Comorbidity } \\
\hline Hypertension & 104 & $(2.05)$ & 44 & $(2.02)$ & 60 & $(2.07)$ \\
\hline Diabetes mellitus & 113 & $(2.22)$ & 72 & $(3.31)$ & 41 & (1.41) \\
\hline Heart disease & 54 & $(1.06)$ & 30 & $(1.38)$ & 24 & $(0.83)$ \\
\hline Chronic pulmonary disease & 54 & $(1.06)$ & 28 & $(1.29)$ & 26 & $(0.9)$ \\
\hline Chronic liver disease & 191 & $(3.76)$ & 105 & $(4.83)$ & 86 & (2.96) \\
\hline Chronic renal disease & 30 & $(0.59)$ & 12 & $(0.55)$ & 18 & $(0.62)$ \\
\hline Cerebrovascular disease & 39 & $(0.77)$ & 18 & $(0.83)$ & 21 & $(0.72)$ \\
\hline Cancer & 92 & $(1.81)$ & 45 & $(2.07)$ & 47 & $(1.62)$ \\
\hline
\end{tabular}

Table 2 Five- and ten-year survival rates and complication-free rates of hip fracture among young adults in Taiwan

\begin{tabular}{|c|c|c|c|c|}
\hline & \multicolumn{2}{|c|}{ Survival rate (\%) } & \multicolumn{2}{|c|}{ Complication-free rate (\%) } \\
\hline & 5-year & 10-year & 5-year & 10-year \\
\hline Total & 95.3 & 93.3 & 75.3 & 73.5 \\
\hline \multicolumn{5}{|l|}{ Gender } \\
\hline Male & 94.7 & 92.5 & 75.7 & 73.6 \\
\hline Female & 97.4 & 96.0 & 74.3 & 72.7 \\
\hline \multicolumn{5}{|l|}{ Fracture } \\
\hline Trochanteric & 94.2 & 91.8 & 82.5 & 80.5 \\
\hline Cervical & 96.1 & 94.5 & 65.7 & 67.3 \\
\hline \multicolumn{5}{|l|}{ Operation } \\
\hline Hemiarthroplasty & 93.0 & 84.0 & 67.2 & 65.4 \\
\hline Internal fixation & 95.4 & 93.6 & 76.1 & 73.8 \\
\hline \multicolumn{5}{|l|}{ CCl No. } \\
\hline 0 & 97.2 & 95.7 & 75.8 & 73.2 \\
\hline 1 & 84.9 & 79.4 & 68.6 & 63.9 \\
\hline$\geq 2$ & 58.8 & 45.7 & 66.9 & 65.9 \\
\hline
\end{tabular}

were chronic liver disease and cirrhosis (15.44\%) and major accidents (10.74\%). (Additional file 1: Table S1).

We explored the effects of risk factors on survival using univariate and multivariate survival analysis (Table 3). Male gender, older age, and greater number of CCI comorbidities were significant risk factors for mortality. Males had 1.60 times (95\% CI: 1.11-2.31) higher HR of overall death than females. The HR increased 1.08 times with each one-year increase in age (95\% CI: 1.05-1.10). Patients with one and two or more CCI comorbidities had higher HRs of overall death compared with those with no CCI comorbidity (HR, 4.08, 95\% CI: 2.84-5.86, and 14.37, 95\% CI: 10.43-19.81, respectively) (Table 3 ).

The 1-month, 3-month, 6-month, 1-year, 2-year, 5-year, and 10-year complication-free rates were 98.3\%, 96.2\%, $94.5 \%, 86.8 \%, 80.4 \%, 75.3 \%$, and $73.5 \%$, respectively, for the entire cohort. The 10-year complication-free rates were $80.5 \%$, and $67.3 \%$ for trochanteric fracture, and cervical fracture, respectively (Table 2) (Figure 1). The complication rate during hospitalization was $4.51 \%$ (Additional file 2: Table S2). We then explored the effects of risk factors for complications after operation with univariate and multivariate Fine and Gray competing risk analysis. Cervical fracture, and greater number of CCI comorbidities were significant risk factors for 
Table 3 (a) Hazard ratios (HR) of risk factors associated with survival time using Cox model, (b) sub-distribution hazard ratios (sHR) of risk factors associated with complication-free time using Fine and Gray's model based on competing risk analysis

\begin{tabular}{|c|c|c|c|c|c|c|c|c|}
\hline & \multicolumn{4}{|c|}{ Survival time } & \multicolumn{4}{|c|}{ Complication-free time } \\
\hline & \multicolumn{2}{|l|}{ Crude $^{\mathrm{a}}$} & \multicolumn{2}{|c|}{ Adjusted $^{b}$} & \multicolumn{2}{|c|}{ Crude $^{a}$} & \multicolumn{2}{|c|}{ Adjusted $^{b}$} \\
\hline & $\mathrm{HR}(95 \% \mathrm{Cl})$ & $p$-value & HR $(95 \% \mathrm{CI})$ & $p$-value & sHR $(95 \% \mathrm{Cl})$ & $p$-value & sHR $(95 \% \mathrm{Cl})$ & $p$-value \\
\hline Age & $1.11(1.08-1.14)$ & $<0.001$ & $1.08(1.05-1.10)$ & $<0.001$ & $1.01(1.00-1.02)$ & 0.275 & $1.00(0.99-1.01)$ & 0.391 \\
\hline \multicolumn{9}{|l|}{ Gender } \\
\hline Female & 1.00 (Reference) & & 1.00 (Reference) & & 1.00 (Reference) & & 1.00 (Reference) & \\
\hline Male & $1.87(1.30-2.67)$ & $<0.001$ & $1.60(1.11-2.31)$ & 0.012 & $0.97(0.85-1.12)$ & 0.683 & $1.04(0.91-1.19)$ & 0.584 \\
\hline Trochanteric & 1.00 (Reference) & & 1.00 (Reference) & & 1.00 (Reference) & & 1.00 (Reference) & \\
\hline Cervical & $0.68(0.52-0.88)$ & 0.003 & $0.84(0.64-1.10)$ & 0.196 & $1.76(1.56-2.00)$ & $<0.001$ & $1.81(1.60-2.06)$ & $<0.001$ \\
\hline Hemiarthroplasty & 1.00 (Reference) & & 1.00 (Reference) & & 1.00 (Reference) & & 1.00 (Reference) & \\
\hline Internal fixation & $0.52(0.31-0.87)$ & 0.013 & $0.87(0.50-1.50)$ & 0.610 & $0.69(0.53-0.93)$ & 0.011 & $0.93(0.70-1.26)$ & 0.632 \\
\hline \multicolumn{9}{|l|}{ CCI No. } \\
\hline 0 & 1.00 (Reference) & & 1.00 (Reference) & & 1.00 (Reference) & & 1.00 (Reference) & \\
\hline 1 & $5.27(3.70-7.51)$ & $<0.001$ & $4.08(2.84-5.86)$ & $<0.001$ & $1.51(1.19-1.89)$ & $<0.001$ & $1.62(1.27-2.03)$ & $<0.001$ \\
\hline$\geq 2$ & $19.19(14.11-26.11)$ & $<0.001$ & 14.37 (10.43-19.81) & $<0.001$ & $1.59(1.16-2.12)$ & 0.003 & $1.68(1.22-2.26)$ & 0.001 \\
\hline
\end{tabular}

${ }^{a}$ Crude HR/sHR: univariable Cox model/ Fine and Gray's model.

${ }^{\mathrm{b}}$ Adjusted HR/sHR: multivariable Cox model/ Fine and Gray's model including age, gender, fracture type, operation type and CCI No.

complications. Cervical fracture had a 1.81 times (95\% CI: 1.60-2.06) higher sHR of complication than trochanteric fracture. Patients with one and two or more CCI comorbidities had higher sHRs of complication compared with those with no CCI comorbidity (sHR, 1.62, 95\% CI: $1.27-2.03$ and $1.68,95 \%$ CI: $1.22-2.26$ respectively) (Table 3). Complications resulted in $42.83 \%$ of patients receiving an internal fixation implant or prosthesis removal and $2.01 \%$ received conversion to or revision arthroplasty during the 11-year follow-up (Additional file 3: Table S3).

\section{Discussion}

We found that the 10 -year survival rate was $>90 \%$. However, the 10 -year complication-free rates were $73.5 \%$, $80.5 \%$, and $67.3 \%$ for total cases, trochanteric fracture, and cervical fracture, respectively. Prevention of severe

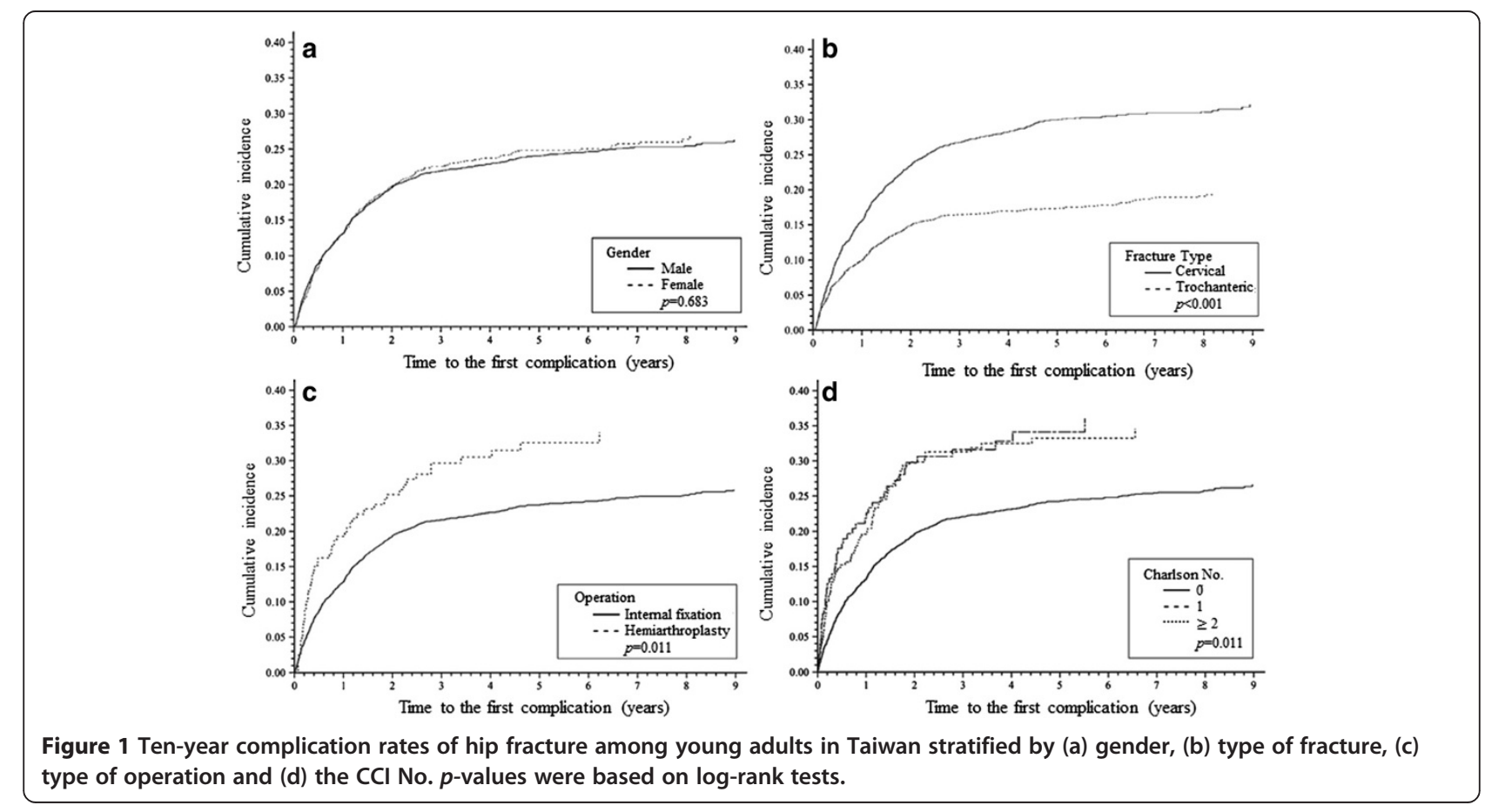


complications after hip fracture among young adults is an important public health issue that warrants greater attention. Few studies have simultaneously explored the survival rate and complication-free rate of hip fractures among young adults. Karantana et al. reported a 10-year survival rate of $86.7 \%$, and the 5 -year internal fixation implant survivorship of women aged $<65$ years with displaced cervical fracture was 71\% [17]. Duckworth et al. explored the long-term results of internal fixation of cervical fracture among young adults aged $<60$ years [19]. The results showed that only 4 (2.6\%) of 152 subjects died within 18 months after surgery and 39 (32\%) of 122 subjects had complications $[17,19]$. These overall complication rates were similar to our findings. The lower survival rate in the aforementioned findings may be attributed to the selection of subjects aged $>40$ years.

We found that the number of CCI comorbidities was a risk factor for both death and complications. Male gender and older age were only statistically significant risk factors for survival. Moreover, fracture type was only a statistically significant risk factor for complications. Duckworth et al. assessed the risk factors for internal fixation failure of cervical fracture among 122 adults aged $<60$ years and found that the presence of preexisting comorbidities was a risk factor [19]. However, Karantana et al. did not identify any significant risk factors leading to internal fixation implant failure because the number of failures was too small [17]. We found cervical fracture had a 1.81 times (95\% CI: $1.60-2.06$ ) higher sHR of complication than trochanteric fracture among young adults. Previous studies have also reported that cervical fracture was associated with a higher complication rate than intertrochanteric fracture among young adults $[13,15]$. Robinson et al. reviewed 75 subjects with hip fracture aged under 50 years and found that only $57(76 \%)$ had satisfactory outcomes [13]. Robinson et al. found that 7 (23\%) of 30 subjects with trochanteric fracture and 14 (31\%) of 45 subjects with cervical fracture had surgical complications [13]. Verttas et al. also reported that cervical fracture had slightly higher complications rates, i.e., $22.5 \%$ for trochanteric fracture and $25 \%$ for cervical fracture, among young adults aged $<50$ years [15]. We found that trochanter fracture had a slightly higher risk for mortality ( $p=0.196)$. Whether trochanteric has a higher risk for mortality or a lower risk for complications than cervical fracture still remains controversial. Previous studies have shown that trochanteric fracture has a higher risk for mortality than cervical fracture among elderly adults [21-25]. Haentjens et al. reported that the 1-year mortality was $27 \%$ for trochanteric fracture and $11 \%$ for cervical fracture [26,27]. However, some studies have reported no significant differences in mortality rates between the two fracture types. Kim et al. reported that cervical fracture had a higher risk for mortality than trochanteric fracture [28].

Several meta-analyses have compared the complication rates between internal fixation and arthroplasty among elderly adults [29-31]. Gao et al. reported that arthroplasty has a lower risk of major complications and better function for displaced cervical fracture among elderly adults in a meta-analysis [29]. Bhandari reported that the relative risk of revision surgery after arthroplasty was 0.23 compared with the risk after internal fixation [31]. Wang et al. reported that arthroplasty had fewer surgical complications among elderly patients at five years postoperatively [30]. Our results differed those reported in previous meta-analyses of elderly adults [29-31]. We found internal fixation had a non-significantly lower hazard of complication than arthroplasty. We postulate that age may explain the differences between our results and previous results. Young adults have a lower death rate and generally have a superior health status compared with elderly patients. Most previous studies investigated elderly patients with hip fracture. Death rates are inevitably higher among these fragile elderly patients. Furthermore, arthroplasty was shown to be associated with a higher mortality rate than internal fixation among elderly patients during follow-up. However, the significantly higher competing death rate among the elderly resulted in fewer subjects exposed to the risk of complications (such as delayed infection and revision) during the follow-up. When the competing death rate is relatively low among young adults, the effect of the competing death rate on complications would be minimal [32].

We found that young adults with a greater number of CCI comorbidities had a higher risk of mortality and complications. Duckworth et al. reported risk factors for fixation failure of cervical fracture among 122 adults aged $<60$ years [19]. They found that alcohol excess, renal disease, liver disease, and respiratory disease were predictive failure factors [19]. Karantana et al. explored 315 hip fractures among young women aged $<65$ years and could not find any significant risk factor leading to internal fixation implant failure because the number of failures was too small. They suspected that smoking and alcohol abuse were important risk factors for mortality [17]. In our database, individual clinical measurements are not available so it was not possible to evaluate these risk factors. We used number of $\mathrm{CCI}$ comorbidities to represent the combined severity of multiple comorbidities that had been demonstrated to be significantly associated with risk of hip fracture [33,34]. No consensus has been reached regarding which comorbidities should be measured, how to quantify the severity of these comorbidities, and how these comorbidities should be placed in a statistical model. 


\section{Limitations}

There were several limitations in this study. Our results were based on young adult patients who were hospitalized with hip fracture for which they had received operation. Subjects with hip fracture were aged 20-40 years and were followed-up for various durations (2-11 years). Selection biases may have existed. ICD-9 CM codes for surgical complications had some variations such that unknown biases may have arisen in the estimation of prevalence rates. We checked all ICD-9 CM codes of our selected subjects to define the surgical complications. Some unknown confounding factors may have existed or changed during the follow-up period. Although we conducted multivariate analysis to examine the risk factors, many risk factors were not adjusted for, such as pre-operative general conditions, smoking/alcohol status and lifestyle, body mass index, bone mineral density, severity of the comorbidity, among others, as these variables were not available in the database. Therefore, caution should be taken in extrapolating our results.

\section{Conclusions}

Among patients with hip fracture aged 20-40 years in Taiwan, the 10-year survival rate was more than $90 \%$, and the 10-year complication-free rate was around $70 \%$. Prevention of the occurrence of severe complications after hip fracture among young adults is an important public health issue that warrants greater attention.

\section{Additional files}

Additional file 1: Table S1. Cause of death among young adults with hip fracture in Taiwan.

Additional file 2: Table S2. Complication rates among hospitalized young adults with hip fracture in Taiwan.

Additional file 3: Table S3. Causes of surgical complications after surgery for hip fracture, stratified by fracture type.

\section{Competing interests}

The authors declare that they have no competing interests.

\section{Authors' contributions}

CFJL, CCW, CL and WML contributed to the study design, conducted the data analysis, and drafted the manuscript. CBW, CFC, and YJC contributed to the data analysis and participated in interpretation of the results. HCW and THL contributed to the study design and manuscript review. All authors read and approved the final manuscript.

\section{Acknowledgements}

The authors would like to thank China Medical University for supporting this research project (CMU102-S-02).

\section{Author details}

${ }^{1}$ Department of Statistics, National Taipei University, Taipei 10478, Taiwan. ${ }^{2}$ Department of Orthopedic Surgery, Wan Fang Hospital, Taipei Medical University, Taipei 11696, Taiwan. ${ }^{3}$ Department of Hospitality Management, Chung Hua University, Hsinchu 30012, Taiwan. ${ }^{4}$ Graduate Institute of Biostatistics, Biostatistics Center, China Medical University, Taichung 40402 , Taiwan. ${ }^{5}$ Department of Public Health, China Medical University, Taichung 40402, Taiwan. ${ }^{6}$ Epidemiology and Biostatistics Center, Changhua Christian
Hospital, Changhua 50006, Taiwan. ${ }^{7}$ Department of Urology, China Medical University Hospital, Taichung 40402, Taiwan. ${ }^{8}$ School of Medicine, China Medical University, Taichung 40402, Taiwan.

Received: 27 January 2014 Accepted: 20 October 2014

Published: 31 October 2014

\section{References}

1. Zuckerman JD: Hip fracture. N Engl J Med 1996, 334(23):1519-1525.

2. Wolinsky FD, Fitzgerald JF, Stump TE: The effect of hip fracture on mortality, hospitalization, and functional status: a prospective study. Am J Public Health 1997, 87(3):398-403.

3. Cummings SR, Melton LJ: Epidemiology and outcomes of osteoporotic fractures. Lancet 2002, 359(9319):1761-1767.

4. Farahmand BY, Michaelsson K, Ahlbom A, Ljunghall S, Baron JA, Swedish Hip Fracture Study G: Survival after hip fracture. OsteoporosInt 2005, 16(12):1583-1590.

5. Court-Brown CM, Caesar B: Epidemiology of adult fractures: A review. Injury 2006, 37(8):691-697.

6. Abrahamsen B, Van Staa T, Ariely R, Olson M, Cooper C: Excess mortality following hip fracture: a systematic epidemiological review. Osteoporosint 2009, 20(10):1633-1650.

7. Haentjens P, Magaziner J, Colon-Emeric CS, Vanderschueren D, Milisen K, Velkeniers B, Boonen S: Meta-analysis: excess mortality after hip fracture among older women and men. Ann Intern Med 2010, 152(6):380-390.

8. Wu TY, Jen MH, Bottle A, Liaw CK, Aylin P, Majeed A: Admission rates and in-hospital mortality for hip fractures in England 1998 to 2009: time trends study. J Public Health 2011, 33(2):284-291.

9. Kim SH, Meehan JP, Blumenfeld T, Szabo RM: Hip fractures in the United States: 2008 nationwide emergency department sample. Arthritis Care Res (Hoboken) 2012, 64(5):751-757.

10. Protzman RR, Burkhalter WE: Femoral-neck fractures in young adults. J Bone Joint Surg Am Vol 1976, 58(5):689-695.

11. Askin SR, Bryan RS: Femoral neck fractures in young adults. ClinOrthopRelat Res 1976, 114:259-264.

12. Swiontkowski MF, Winquist RA, Hansen ST Jr: Fractures of the femoral neck in patients between the ages of twelve and forty-nine years. J Bone Joint Surg Am Vol 1984, 66(6):837-846.

13. Robinson CM, Court-Brown CM, McQueen MM, Christie J: Hip fractures in adults younger than 50 years of age. Epidemiology and results. ClinOrthopRelat Res 1995, 312:238-246.

14. Hwang LC, Lo WH, Chen WM, Lin CF, Huang CK, Chen CM: Intertrochanteric fractures in adults younger than 40 years of age. Arch Orthop Trauma Surg 2001, 121(3):123-126.

15. Verettas DA, Galanis B, Kazakos K, Hatziyiannakis A, Kotsios E: Fractures of the proximal part of the femur in patients under 50 years of age. Injury 2002, 33(1):41-45.

16. Platzer $P$, Thalhammer $G$, Wozasek GE, Vecsei V: Femoral shortening after surgical treatment of trochanteric fractures in nongeriatric patients. J Trauma 2008, 64(4):982-989.

17. Karantana A, Boulton C, Bouliotis G, Shu KS, Scammell BE, Moran CG: Epidemiology and outcome of fracture of the hip in women aged 65 years and under: a cohort study. J Bone Joint Surg Br Vol 2011, 93(5):658-664

18. Min BW, Kim SJ: Avascular necrosis of the femoral head after osteosynthesis of femoral neck fracture. Orthopedics 2011, 34(5):349.

19. Duckworth AD, Bennet SJ, Aderinto J, Keating JF: Fixation of intracapsular fractures of the femoral neck in young patients: risk factors for failure. J Bone Joint Surg Br Vol 2011, 93(6):811-816.

20. Charlson ME, Pompei P, Ales KL, Mackenzie CR: A new method of classifying prognostic comorbidity in longitudinal studies: development and validation. J Chronic Dis 1987, 40(5):373-383.

21. Lu-Yao GL, Baron JA, Barrett JA, Fisher ES: Treatment and survival among elderly Americans with hip fractures: a population-based study. Am J Public Health 1994, 84(8):1287-1291

22. Muraki S, Yamamoto S, Ishibashi H, Nakamura K: Factors associated with mortality following hip fracture in Japan. J Bone Miner Metab 2006, 24(2):100-104.

23. Haentjens $P$, Autier P, Barette M, Venken K, Vanderschueren D, Boonen S, Hip Fracture Study G: Survival and functional outcome according to hip fracture type: a one-year prospective cohort study in elderly women 
with an intertrochanteric or femoral neck fracture. Bone 2007, 41(6):958-964.

24. Holt G, Smith R, Duncan K, Finlayson DF, Gregori A: Early mortality after surgical fixation of hip fractures in the elderly: an analysis of data from the scottish hip fracture audit. J Bone Joint Surg Br Vol 2008, 90(10):1357-1363.

25. Lin WP, Wen CJ, Jiang CC, Hou SM, Chen CY, Lin J: Risk factors for hip fracture sites and mortality in older adults. J Trauma 2011, 71(1):191-197.

26. Kesmezacar H, Ayhan E, Unlu MC, Seker A, Karaca S: Predictors of mortality in elderly patients with an intertrochanteric or a femoral neck fracture. J Trauma 2010, 68(1):153-158.

27. Castronuovo E, Pezzotti P, Franzo A, DiLallo D, Guasticchi G: Early and late mortality in elderly patients after hip fracture: a cohort study using administrative health databases in the Lazio region, Italy. BMC Geriatr 2011, 11:37.

28. Kim SM, Moon YW, Lim SJ, Yoon BK, Min YK, Lee DY, Park YS: Prediction of survival, second fracture, and functional recovery following the first hip fracture surgery in elderly patients. Bone 2012, 50(6):1343-1350.

29. Gao H, Liu Z, Xing D, Gong M: Which is the best alternative for displaced femoral neck fractures in the elderly?: A meta-analysis. ClinOrthopRelat Res 2012, 470(6):1782-1791.

30. Wang J, Jiang B, Marshall RJ, Zhang P: Arthroplasty or internal fixation for displaced femoral neck fractures: which is the optimal alternative for elderly patients? A meta-analysis. IntOrthop 2009, 33(5):1179-1187.

31. Bhandari M, Devereaux PJ, Swiontkowski MF, Tornetta P 3rd, Obremskey W, Koval K, Nork S, Spraque S, Schemitsch EH, Guyatt GH: Internal fixation compared with arthroplasty for displaced fractures of the femoral neck. A meta-analysis. J Bone Joint Surg Am Vol 2003, 85-A(9):1673-1681.

32. Dignam JJ, Kocherginsky MN: Choice and interpretation of statistical tests used when competing risks are present. J ClinOncol 2008, 26(24):4027-4034.

33. Radley DC, Gottlieb DJ, Fisher ES, Tosteson AN: Comorbidity risk-adjustment strategies are comparable among persons with hip fracture. J ClinEpidemio 2008, 61(6):580-587.

34. Kirkland LL, Kashiwagi DT, Burton MC, Cha S, Varkey P: The Charlson Comorbidity Index Score as a predictor of 30-day mortality after hip fracture surgery. Am J Med Qual 2011, 26(6):461-467.

doi:10.1186/1471-2474-15-362

Cite this article as: Lin et al:: Mortality and complications of hip fracture in young adults: a nationwide population-based cohort study. BMC

Musculoskeletal Disorders 2014 15:362.

\section{Submit your next manuscript to BioMed Central and take full advantage of:}

- Convenient online submission

- Thorough peer review

- No space constraints or color figure charges

- Immediate publication on acceptance

- Inclusion in PubMed, CAS, Scopus and Google Scholar

- Research which is freely available for redistribution 